\title{
The Effect of Foot Massage on Pain of the Intensive Care Patients: A Parallel Randomized Single-Blind Controlled Trial
}

\author{
Masoumeh Momeni, ${ }^{1}$ Mansoor Arab, ${ }^{2}$ Mahlagha Dehghan (iD, ${ }^{3}$ and Mehdi Ahmadinejad ${ }^{4}$ \\ ${ }^{1}$ Student Research Committee, School of Nursing and Midwifery, Kerman University of Medical Sciences, Kerman, Iran \\ ${ }^{2}$ Faculty of Nursing and Midwifery, Bam University of Medical Sciences, Bam, Iran \\ ${ }^{3}$ Nursing Research Center, Department of Critical Care Nursing, School of Nursing and Midwifery, \\ Kerman University of Medical Sciences, Kerman, Iran \\ ${ }^{4}$ Department of Critical Care Medicine, Kerman University of Medical Sciences, Kerman, Iran \\ Correspondence should be addressed to Mahlagha Dehghan; m_dehghan86@yahoo.com
}

Received 10 January 2020; Revised 26 March 2020; Accepted 6 April 2020; Published 13 June 2020

Academic Editor: Andreas Sandner-Kiesling

Copyright (C) 2020 Masoumeh Momeni et al. This is an open access article distributed under the Creative Commons Attribution License, which permits unrestricted use, distribution, and reproduction in any medium, provided the original work is properly cited.

\begin{abstract}
Background and Purpose. Pain is a common stressor in intensive care units (ICUs) with detrimental consequences in case of no treatment. The current study aimed to compare the effect of foot massage by a nurse or the patient's family on pain of the ICU patients. Materials and Methods. This randomized, parallel, single-blind controlled trial study was performed on 75 ICU patients. Patients were allocated into three groups (massage by a nurse, massage by the patient's family, and control group) by the minimization method. Swedish massage was provided for the patients in experimental groups (each foot for 5 minutes) once a day for six days. The pain was examined in all three groups before, immediately, and one week after the intervention. Results. The mean scores of pain in the groups of foot massage by the patient's family and by a nurse showed a significant reduction at the end of the study (from 4.48 to 3.36 and 4.76 to 2.96 , respectively). The control group had significantly more pain after the intervention than the family-based massage group and the nurse-based massage group $(P<0.05)$. Although significant difference was found in the mean scores of pain between the massage provided by a nurse and that provided by the patient's family immediately after the intervention $(P<0.05)$, it was not significant one week after the intervention $(P>0.05)$. Conclusion. Using foot massage, by both nurses and family members can reduce the pain of ICU patients. This intervention may improve the nursing care quality with the least cost and complications.
\end{abstract}

\section{Introduction}

Pain is an unpleasant sensory, emotional, and mental experience after real or potential tissue damage $[1,2]$. Pain in the intensive care unit (ICU) is more common than that in the general wards, with $45 \%-82 \%$ of the ICU patients undergoing different degrees of pain [3]. The ICU patients' pain may not be treated due to low levels of consciousness, sedative drugs, and mechanical ventilation [1]. Pain and anxiety affects the nervous system resulting in the release of catecholamines and the formation of dysrhythmia, changes in vital signs, myocardial ischemia, mental disorders and delirium, delayed wound healing, poor sleep quality, agitation, patient's fighting the ventilator, and removal of catheters by the patient, a prolonged stay in ICU, re-admission, patient's dissatisfaction with medical care, and ultimate illness and increased mortality $[4,5]$. During ICU treatment, $40-68 \%$ of patients experience moderate to severe pain $[6,7]$. Puntillo et al. reported that half of the procedures in ICUS such as endotracheal and tracheal suctioning, chest tube removal, wound drain removal, turning, and arterial line insertion, increased the risk of patients having higher degrees of pain distress by at least $30 \%$ [8]. In addition, $38.2-66 \%$ of the intensive care survivors experience chronic pain up to one year after discharge $[9,10]$. Therefore, the perception of a stressful experience is a key to recover from a critical illness: staff and family members should carefully evaluate different 
stressors while trying to avoid over- and underestimation [11].

Although pain activates a large number of pathophysiological mechanisms in the ICU patients, the rate of pain assessment in the ICU is low [12]. Rose et al. reported that nurses did not tend to use pain assessment tools in verbally disabled patients, and they had little information about new guidelines of pain controls that can have a negative effect on their performance in controlling the pain of patients [13]. Although recent guidelines support analgesics before nursing and medical procedures, it is unusual to administer analgesics before procedures $[14,15]$. However, $30-60 \%$ of the ICU patients receive deep and long-term sedatives [16]. Opioids are the most frequently used drugs for pain relief in the ICUs. In addition, nonsteroidal anti-inflammatory drugs can be used to reduce the pain of the ICU patients [17]. Recently, light sedatives have been increasingly taken due to negative consequences of deep sedatives such as increased anxiety, stress, delirium, long stay, and infection risk $[18,19]$. In addition, nonpharmaceutical methods can be used: aromatherapy, acupuncture, music therapy, biofeedback techniques, massage therapy, relaxation techniques, and reflexology [20].

In recent years, complementary medicines have been widely considered accompanying the standard treatment. Massage therapy, a type of complementary medicine, stimulates the nerves, tactile receptors and sends nervous impulses to the brain [21]. Massage reduces the patient's blood pressure and heart rate and makes him/her feel comfortable and relaxed [22]. Following the relaxation of the muscles, the endorphin is produced that improves sleep quality and alleviates pain and muscle cramps, and thus a pleasant sense is created and the need for sedatives reduces [23].

Different studies assessed the effect of massage on painrelieving in the ICU patients. The results showed the effect of different types of massage therapies on pain relief of the ICU patients [20,24-26]. Also, many studies have shown the role of family members in the care of ICU patients $[27,28]$. A good health outcome in family-centered care approach will be achieved when the family members of the patient play an active role in physical, psychological, and emotional and social support [29]. Black et al. argued that the familycentered care strengthened the patient's defense lines, increased his/her resistance against stressors during acute illness, and improved his/her mental health [30]. Studies show that families receive more attention, support, and collaboration from nursing staff when participating in patient care [31-33].

Regarding the importance of evaluating and controlling pain in intensive care units and considering the destructive effects of sedatives and narcotics, complementary medicines can alleviate the pain of these patients [34]. Nurses can use nonpharmacological methods such as massage in intensive care units to control pain because they are simple, inexpensive, and easy-to-use. However, few studies have compared the effect of massage by nurses and family members on pain of the ICU patients. Regarding the nurses' workload and shortage, family involvement in the patient care may improve the patients' quality of care. Therefore, the present study aimed to compare the effect of foot massage by a nurse and the patient's family on pain of the ICU patients.

\section{Materials and Methods}

2.1. Study Design and Setting. This randomized, parallel, single-blind controlled trial has been conducted in the ICUs of Shahid Bahonar hospital in Kerman in 2017. Shahid Bahonar hospital, a trauma ICU center in southeastern Iran, has three trauma intensive care units and 46 beds.

2.2. Sample Size and Sampling. The samples were selected using consecutive sampling method, and they were allocated into three groups (two groups of intervention and one control group) by stratified randomization method. The patients were allocated to each group after being checked in terms of sex and addiction history and then by drawing dice. This process continued until the end of sampling. The first author enrolled the participants and assigned them to the three groups. The inclusion criteria were as follows: patients who were supposed to be in the ICUs at least for two weeks, patients with tracheal tube or tracheostomy [35], discontinuous infusion of sedative drugs such as midazolam and propofol [36], discontinuous infusion of narcotics such as fentanyl [27], patients aged between 15 and 50 years [35], with no withdrawal syndrome [37], no foot vascular disease, such as deep venous thrombosis [38], no fractures in the lower extremities [38], no skin disease, ulcers, and infections of feet [19]. Exclusion criteria include the patient's extubation [35], reduction in the level of consciousness to less than 9 due to hypoxia or/and increased intracranial pressure [37], no referral of the patient's family to the ward for massage for more than two days, patient's death, and discharge [35]. Previous studies were used for the estimation of sample size [39]. The confidence coefficient, the confidence interval, and the type-II-error were 95\%, 1.96, and $10 \%$, respectively (the study power $=90 \%$ ). According to the three study groups, the sample size was adjusted and the number of samples needed for this study was 21 in each group. However, 25 samples were considered in each group (Figure 1) to improve the study power.

2.3. Measurements. The data-gathering tool in this study was the sociodemographic and clinical information questionnaire and behavioral pain scale (BPS). The sociodemographic and clinical information questionnaire included age, sex, marital status, occupation, level of education, history of admission to intensive care units, history of other illnesses, history of addiction, history of smoking, history of seizure, history of hypertension, duration of stay in the ICU, history of surgery during hospitalization, type of disease, and vital signs. BPS was used to assess pain. Payen et al. developed BPS in 2001. The scale has three items: facial appearance, status of upper limbs, and ventilator compatibility. Dehghani et al. investigated the validity and reliability of the scale. These results showed that the scores of behavioral pain scale were significantly different during painful and nonpainful procedures. Also, Cronbach's alpha was 85 for 


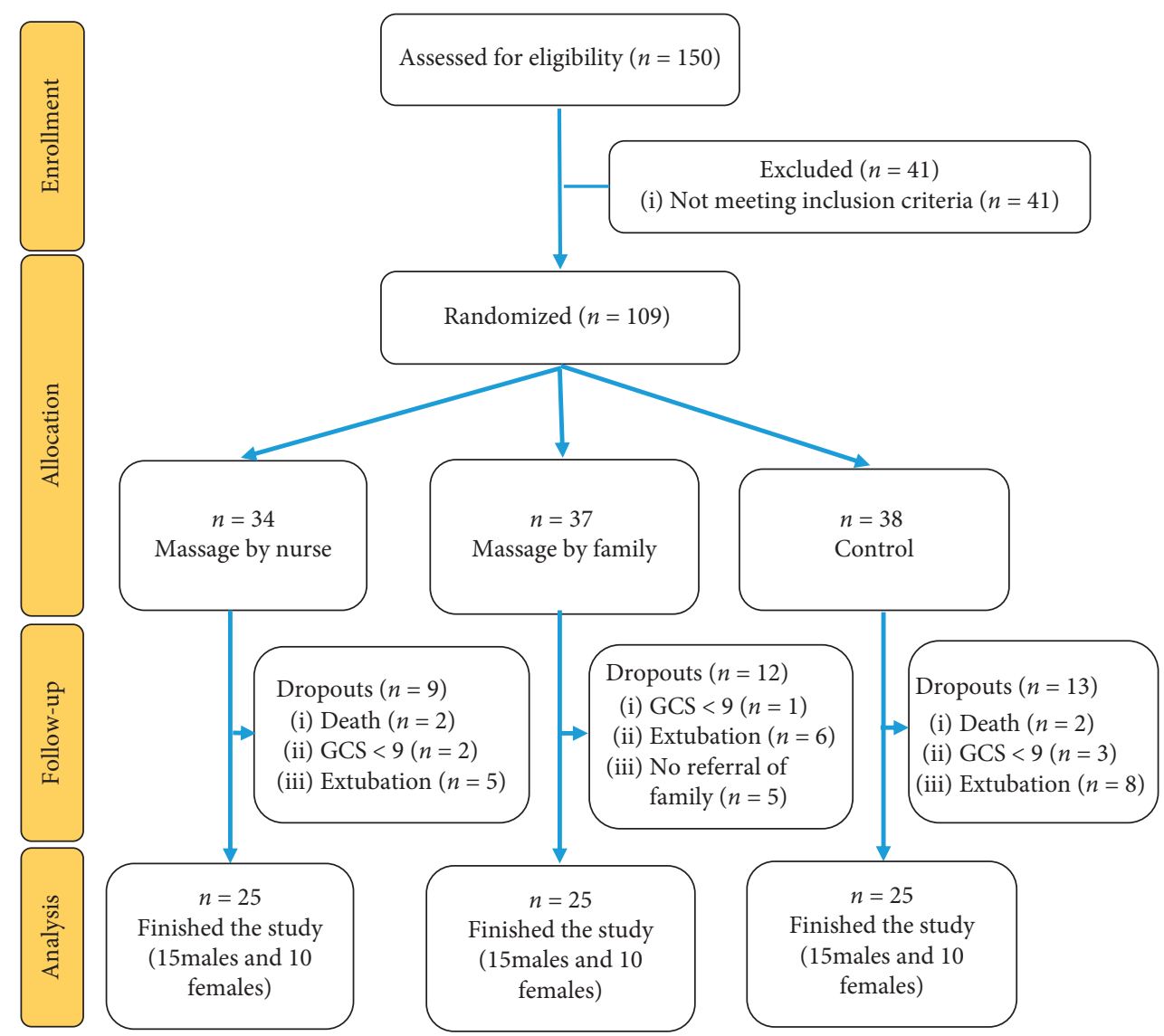

Figure 1: The flow diagram of the study.

painful procedures and 76 for nonpainful procedures [40]. Yaghoubiana et al. reported the reliability of this scale to be $0.86[20]$.

\subsection{Data Collection and Intervention. The researcher went to} Shahid Bahonar hospital in Kerman and obtained informed consent from the patient's family after receiving the code of ethics and the clinical trial registration code as well as coordinating with the head of the hospital and the authorities of the intensive care units. The coresearcher received sufficient training and measured the pain variable in three groups before the massage without being aware of the samples assignment. A physiotherapist trained the first researcher (ICU nurse) how to massage. In the intervention groups, in addition to routine care, a nurse or a family member of the patients performed Swedish massage on their feet (from knee to toes) for six consecutive days for 10 minutes ( 5 minutes for each foot). The massage procedure was as follows: first, the patient was placed in a supine position with a pillow under the feet so that the feet were bent slightly and the head was at an angle of 30-45 degrees. The massage area was uncovered from $10 \mathrm{~cm}$ above the patient's knee. Then, the researcher (the nurse) began to massage after examining the feet for the presence of the massage barriers. The Swedish massage included stroking, effleurage, vibrations, or kneading. Baby oil was used to make the area slippery and easy-to-massage (about 1-2 cc per foot), and it had no other therapeutic value. The massage was performed at $15-17 o^{\prime}$ clock when the workload of the intensive care unit was low. A napkin was used to remove the residual oil on the patient's body. The first researcher, who was a nurse of the intensive care unit, performed all massages. In addition, she trained one or two family members of the patient how to massage, and they initiated the intervention after her confirmation. The control group only received routine care. The pain was reexamined in all three groups immediately (sixth day) and one week after the intervention (thirteenth day). A coresearcher, who was not aware of the patients' assignment, assessed all measurements.

2.5. Data Analysis. Data were analyzed by SPSS 18 . Descriptive statistics (frequency, percentage, mean, and standard deviation) were used to describe patients' demographic characteristics and clinical information. Mean and standard deviation were used to describe the pain score. Chi-squared test, Fisher's exact test, Kruskal-Wallis test, and ANOVA were used to examine the similarity of the three groups regarding the study variables. Regarding the establishment of parametric conditions (normal distribution and equality of variances in the three groups), the two-way factorial ANOVA test was used to compare the pain score before, 
immediately, and one week after the intervention within and between the three groups. The post hoc test of Bonferroni used for multiple comparisons.

2.6. Ethical Considerations. Kerman University of Medical Sciences approved the study protocol (No. ir.kmu.rec.1396.1460). The study protocol was registered to the Iran RCT center (No. IRCT201707317844N12). The researcher obtained informed consent from the patient's guardian.

\section{Results}

The mean age of the samples in the family-based massage group was $41.12 \pm 9.29$, and it was $39.49 \pm 10.79$ in the nursebased massage group and $42.8 \pm 6.65$ in the control group. No statistically significant difference was found among the three groups in the mean age $(P=0.42)$. Sixty percent $(n=15)$ of the samples were men. Sixty-eight percent $(n=17)$ of the samples in the family-based massage group, $76 \%(n=19)$ of the samples in the nurse-based massage group, and $84 \%(n=21)$ of the samples in the control group were married $\left(P=0.42: \chi^{2}=1.75\right)$. In addition, no statistically significant difference was found among the three groups in occupation $(P=0.96)$ and education levels $(P=0.24)$. No differences were observed in the medical history among the three groups (Table 1).

The level of consciousness was nine in all three groups based on the Glasgow coma scale. The length of stay in the ICU was five to six days in all three groups before the study $(P=0.06)$. Eighty-four percent of the samples in the familybased massage group, $88 \%$ in the nurse-based massage group, $92 \%$ in the control group had the tracheal tube, and the rest had a tracheostomy $(P=0.90)$. No statistically significant difference was found among the three groups in the rate of spontaneous breathing $(P=0.49)$, the rate of assisted spontaneous breathing $(P=0.59)$, the rate of inspired oxygen $(P=0.37)$, and the positive end-expiratory pressure $(P=0.90)$. The administration of narcotics (midazolam, propofol, morphine, methadone, fentanyl, and opium) and nonnarcotics (nitroglycerin, metoral, hydrochlorothiazide, propranolol, and dopamine) was not significantly different among the three groups before the intervention $(P>0.05)$. In addition, no significant differences were found among the three groups in the mean arterial blood pressure $(P=0.28)$, heart rate $(P=0.08)$, and arterial blood saturation $(P=0.61)$ at the beginning of the study.

The mean score of pain in the three groups at different times is presented in Table 2. The results of two-way ANOVA showed a statistically significant group-time interaction which indicates that the pain scores were different between groups at different times (Table 3). The withinsubject comparisons showed, in the control group, the pain alleviation at the different times were not significant. In both massage groups, the pain alleviation immediately and one week after intervention compared with that before intervention was significant; however, the pain alleviation immediately after intervention compared with that one week after intervention was not significant (Table 4).

Multiple comparisons showed the pain scores were not different between groups before the intervention. Immediately after intervention, patients in the nurse-based massage group had significantly less pain than those of the familybased massage group and the control group. One week after intervention, patients in the nurse-based massage group and the family-based massage group had significantly less pain than those of the control group. One week after intervention, there were no differences between the two massage groups (Table 5).

\section{Discussion}

The results of the present study showed that the mean score of pain in patients admitted to intensive care units was mild. A six-day foot massage either by the family or a nurse significantly reduced the mean score of pain compared with routine care (control group). Few studies compared the effect of massage performed by the family and a nurse on pain of the ICU patients [25]. Jamaati et al. showed that the whole-body massage by a nurse and the patient's family for 30 minutes reduced the pain score in the ICU patients with the consciousness level of 10-15 [25]. Similar to the results of this study, massage reduced pain in the study of Jamaati et al. However, unlike the results of this study, family-based massage had a greater effect on the pain-relief compared with the nurse-based massage [29]. The reason for the differences might be the LOC of ICU patients.

Several studies have examined the effect of massage by the family or a nurse on pain of the ICU patients. Najafi et al. showed a reduced pain intensity in patients undergoing coronary artery bypass graft surgery after being massaged by the their family caregivers [41]. Cutshall et al. showed that the Swedish massage of the whole body after the coronary artery bypass graft surgery significantly reduced the pain, anxiety, and tension of the muscles [42]. Yaghoubinia et al. showed that the foot massage reduced the pain score in unconscious ICU patients [20]. Braun et al. found that the Swedish massage decreased the pain after the surgery compared with that of the control group [26]. Babajani et al. studied the pain intensity while removing a chest tube after open-heart surgery and showed that the pain score reduced in foot reflexology massage groups compared with the control and placebo groups [24]. Also, Imani et al. showed that reflexology massage could reduce the intensity of nitroglycerin-induced migraine-type headache in the CCU patients [43]. The results of the above studies support the results of the present study. Although there are many differences among the patients in various studies, the type, duration and areas of the massage, and pain measuring instruments, all studies confirmed the effect of massage on pain. Several theories have been proposed to describe the mechanisms of massage therapy. One is the gate control theory for pain relief suggesting that massage has an analgesic effect [44]. The second one is that massage can relax the patient and reduce pain by improving the secretion of endorphins, increasing 
TABLE 1: Comparison of the medical history in the family-based massage group, nurse-based massage group, and control.

\begin{tabular}{|c|c|c|c|c|c|c|c|c|}
\hline \multirow{3}{*}{ Variable } & \multicolumn{8}{|c|}{ Group } \\
\hline & \multicolumn{2}{|c|}{$\begin{array}{l}\text { Family-based } \\
\text { massage group }\end{array}$} & \multicolumn{2}{|c|}{$\begin{array}{l}\text { Nurse-based } \\
\text { massage group }\end{array}$} & \multicolumn{2}{|c|}{ Control group } & \multirow[t]{2}{*}{ Statistical test } & \multirow[t]{2}{*}{$P$ value } \\
\hline & Frequency & Percent & Frequency & Percent & Frequency & Percent & & \\
\hline \multicolumn{9}{|l|}{ History of admission in ICU } \\
\hline Yes & 2 & 8.0 & 4 & 16.0 & 2 & 8.0 & \multirow{2}{*}{$1.08^{*}$} & \multirow{2}{*}{0.72} \\
\hline No & 23 & 92.0 & 21 & 84.0 & 23 & 92.0 & & \\
\hline \multicolumn{9}{|l|}{ History of other diseases } \\
\hline Yes & 11 & 44.0 & 12 & 48.0 & 12 & 48.0 & \multirow{2}{*}{$0.11^{* *}$} & \multirow{2}{*}{$>0.99$} \\
\hline No & 14 & 56.0 & 13 & 52.0 & 13 & 52.0 & & \\
\hline \multicolumn{9}{|l|}{ Current history of addiction } \\
\hline Yes & 11 & 44.0 & 11 & 44.0 & 11 & 44.0 & \multirow{2}{*}{-} & \multirow{2}{*}{-} \\
\hline No & 14 & 56.0 & 14 & 56.0 & 14 & 56.0 & & \\
\hline \multicolumn{9}{|l|}{ History of smoking } \\
\hline Yes & 9 & 36.0 & 7 & 28.0 & 9 & 36.0 & \multirow{2}{*}{$0.48^{* *}$} & \multirow{2}{*}{0.86} \\
\hline No & 16 & 64.0 & 18 & 72.0 & 16 & 64.0 & & \\
\hline \multicolumn{9}{|l|}{ History of seizure } \\
\hline Yes & 0 & 0.0 & 3 & 12.0 & 0 & 0.0 & \multirow[b]{2}{*}{$4.26^{*}$} & \multirow[b]{2}{*}{0.10} \\
\hline No & 25 & 100.0 & 22 & 88.0 & 25 & 100.0 & & \\
\hline \multicolumn{9}{|l|}{ Hypertension } \\
\hline Yes & 10 & 40.0 & 10 & 40.0 & 9 & 36.0 & \multirow{2}{*}{$0.11^{*}$} & \multirow{2}{*}{0.94} \\
\hline No & 15 & 60.0 & 15 & 60.0 & 16 & 64.0 & & \\
\hline \multicolumn{9}{|c|}{ History of taking hypertension medications } \\
\hline Yes & 10 & 40.0 & 9 & 36.0 & 9 & 36.0 & \multirow{2}{*}{$0.11^{* *}$} & \multirow{2}{*}{0.99} \\
\hline No & 15 & 60.0 & 16 & 64.0 & 16 & 64.0 & & \\
\hline \multicolumn{9}{|c|}{ History of surgery during hospitalization } \\
\hline Yes & 21 & 84.0 & 20 & 80.0 & 20 & 80.0 & \multirow{2}{*}{$0.26^{*}$} & \\
\hline No & 4 & 16.0 & 5 & 20.0 & 5 & 20.0 & & 0.99 \\
\hline Type of disease & & & & & & & & \\
\hline Lesions with bleeding & 6 & 24.0 & 9 & 36.0 & 9 & 36.0 & & \\
\hline Lesions without bleeding & 19 & 0.76 & 16 & 0.64 & 16 & 0.64 & $1.10^{* * 4}$ & 0.70 \\
\hline
\end{tabular}

${ }^{*}$ Fisher's exact test; ${ }^{* *}$ Chi-squared test.

TABLE 2: The pain score in the family-based massage group, nurse-based massage group, and control at different times.

\begin{tabular}{|c|c|c|c|}
\hline \multirow[b]{2}{*}{ Pain score } & \multicolumn{3}{|c|}{ Group } \\
\hline & $\begin{array}{c}\text { Family-based massage group } \\
\text { Mean (SD) }\end{array}$ & $\begin{array}{c}\text { Nurse-based massage group } \\
\text { Mean (SD) }\end{array}$ & $\begin{array}{l}\text { Control group } \\
\text { Mean (SD) }\end{array}$ \\
\hline Before intervention & $4.48(0.77)$ & $4.76(1.13)$ & $4.28(1.14)$ \\
\hline Immediately after intervention & $3.64(0.70)$ & $2.88(0.78)$ & $4.20(0.76)$ \\
\hline One week after the intervention & $3.36(0.64)$ & $2.96(0.67)$ & $4.00(0.71)$ \\
\hline
\end{tabular}

SD: standard deviation.

TABLE 3: Comparison of pain in the family-based massage group, nurse-based massage group, and control at different times.

\begin{tabular}{lccccc}
\hline Source of change & Sum of squares & $\mathrm{d} f$ & $F$ & $P$ value & Partial Eta squared \\
\hline Group & 14.75 & 2 & 10.69 & $<0.001$ & 0.09 \\
Time & 50.67 & 2 & 36.74 & $<0.001$ & 0.25 \\
Group * Time & 23.87 & 4 & 8.65 & $<0.001$ & 0.14 \\
Error & 148.96 & 216 & & & \\
\hline
\end{tabular}

the activity of the parasympathetic system, and decreasing the production of stress hormones [23, 45]. The third theory suggests that manipulating the skeletal-muscular system releases tension from muscle fibers and connective tissue [46].
The results of the present study and available evidence suggest that massage by trained nurses or family members of patient can reduce the pain of ICU patients. Therefore, considering the importance of family-centered care, nurses' workload, and shortage, families can provide massage, and 
TABLE 4: Adjustment for multiple comparisons using Bonferroni for the comparison of pain within the family-based massage group, nursebased massage group, and control at different times.

\begin{tabular}{|c|c|c|c|c|c|c|}
\hline Group & Time $(I)$ & Time $(J)$ & $\begin{array}{c}\text { Mean difference } \\
(I-J)\end{array}$ & $\begin{array}{c}\text { Standard } \\
\text { error }\end{array}$ & $\begin{array}{c}P \\
\text { value }\end{array}$ & $\begin{array}{l}95 \% \text { confidence interval } \\
\text { for difference }\end{array}$ \\
\hline \multirow{3}{*}{$\begin{array}{l}\text { Family-based } \\
\text { massage group }\end{array}$} & \multirow{2}{*}{ Before } & $\begin{array}{l}\text { Immediately after } \\
\text { intervention }\end{array}$ & 0.84 & 0.24 & 0.001 & $0.27-1.41$ \\
\hline & & $\begin{array}{l}\text { One week after the } \\
\text { intervention }\end{array}$ & 1.12 & 0.24 & $<0.001$ & $0.55-1.69$ \\
\hline & $\begin{array}{c}\text { Immediately after } \\
\text { intervention }\end{array}$ & $\begin{array}{l}\text { One week after the } \\
\text { intervention }\end{array}$ & 0.28 & 0.24 & 0.70 & $-0.29-0.85$ \\
\hline \multirow{3}{*}{$\begin{array}{l}\text { Nurse-based } \\
\text { massage group }\end{array}$} & \multirow{2}{*}{ Before } & $\begin{array}{l}\text { Immediately after } \\
\text { intervention }\end{array}$ & 1.88 & 0.24 & $<0.001$ & $1.31-2.45$ \\
\hline & & $\begin{array}{l}\text { One week after the } \\
\text { intervention }\end{array}$ & 1.80 & 0.24 & $<0.001$ & $1.23-2.37$ \\
\hline & $\begin{array}{l}\text { Immediately after } \\
\text { intervention }\end{array}$ & $\begin{array}{l}\text { One week after the } \\
\text { intervention }\end{array}$ & -0.08 & 0.24 & $>0.99$ & $-0.65-0.49$ \\
\hline \multirow{3}{*}{ Control group } & \multirow[b]{2}{*}{ Before } & $\begin{array}{l}\text { Immediately after } \\
\text { intervention }\end{array}$ & 0.08 & 0.24 & $>0.99$ & $-0.49-0.65$ \\
\hline & & $\begin{array}{l}\text { One week after the } \\
\text { intervention }\end{array}$ & 0.28 & 0.24 & 0.70 & $-0.29-0.85$ \\
\hline & $\begin{array}{c}\text { Immediately after } \\
\text { intervention }\end{array}$ & $\begin{array}{l}\text { One week after the } \\
\text { intervention }\end{array}$ & 0.20 & 0.24 & $>0.99$ & $-0.37-0.77$ \\
\hline
\end{tabular}

TABle 5: Adjustment for multiple comparisons using Bonferroni for the comparison of pain between the family-based massage group, nurse-based massage group, and control at different times.

\begin{tabular}{|c|c|c|c|c|c|c|}
\hline Time & Group (I) & Group $(J)$ & $\begin{array}{c}\text { Mean difference } \\
(I-J)\end{array}$ & $\begin{array}{l}\text { Standard } \\
\text { error }\end{array}$ & $\begin{array}{c}P \\
\text { value }\end{array}$ & $\begin{array}{l}95 \% \text { confidence interval } \\
\text { for difference }\end{array}$ \\
\hline \multirow{3}{*}{ Before } & \multirow{2}{*}{$\begin{array}{l}\text { Family-based } \\
\text { massage group }\end{array}$} & $\begin{array}{l}\text { Nurse-based } \\
\text { massage group }\end{array}$ & 0.28 & 0.24 & 0.70 & $-0.85-0.29$ \\
\hline & & Control group & 0.20 & 0.24 & $>0.99$ & $-0.37-0.77$ \\
\hline & $\begin{array}{l}\text { Nurse-based } \\
\text { massage group }\end{array}$ & Control group & 0.48 & 0.24 & 0.13 & $-0.09-1.05$ \\
\hline \multirow{3}{*}{$\begin{array}{l}\text { Immediately after } \\
\text { intervention }\end{array}$} & \multirow{2}{*}{$\begin{array}{l}\text { Family-based } \\
\text { massage group }\end{array}$} & $\begin{array}{l}\text { Nurse-based } \\
\text { massage group }\end{array}$ & 0.76 & 0.24 & 0.004 & $0.19-1.38$ \\
\hline & & Control group & -0.56 & 0.24 & 0.05 & $-1.13-0.007$ \\
\hline & $\begin{array}{l}\text { Nurse-based } \\
\text { massage group }\end{array}$ & Control group & -1.32 & 0.24 & $<0.001$ & -1.89 to -0.75 \\
\hline \multirow{3}{*}{$\begin{array}{l}\text { One week after the } \\
\text { intervention }\end{array}$} & \multirow{2}{*}{$\begin{array}{l}\text { Family-based } \\
\text { massage group }\end{array}$} & $\begin{array}{l}\text { Nurse-based } \\
\text { massage group }\end{array}$ & 0.40 & 0.24 & 0.27 & $-0.17-0.97$ \\
\hline & & Control group & -0.64 & 0.24 & 0.02 & -1.21 to -0.07 \\
\hline & $\begin{array}{l}\text { Nurse-based } \\
\text { massage group }\end{array}$ & Control group & -1.04 & 0.24 & $<0.001$ & -1.61 to -0.47 \\
\hline
\end{tabular}

involving families in massages can lead to effective interventions after patients' discharge from the hospital. However, nurses should train patients and their families properly $[32,41]$. In addition, training different skills of complementary and alternative methods, particularly massage to nursing students may improve their ability to provide better nursing care for the patients.

One of the limitations of this study was the lack of cooperation of some families. No information about the disease and the effect of massage on the patient and difficulty to attend in the hospital for six consecutive days were the causes of this limitation. This limitation was eliminated by training the family and reducing their concerns as well as by contacting with families who were not present at a proper time. In addition, two family members who provided the massages might influence the results. However, only seven cases were massaged by two family members (3-4 sessions with one family member and 1-2 sessions with another member). As the majority of the sessions were provided with the same family members, the data were analyzed on a perprotocol basis and not an intention to treat. The study samples did not represent all patients in the intensive care unit, so the results could not be generalized to other patients admitted to the intensive care unit. In addition, the first researcher allocated the samples into groups, which may be associated with bias. 


\section{Conclusion}

According to the results of this study, our hypothesis is approved. On the other hand, the mean scores of pain was significantly different among the family-based massage group, the nurse-base massage group, and the control group after the intervention. The mean pain scores in the familybased massage group and the nurse-based massage group significantly decreased after the intervention, but the mean pain score in the control group did not significantly decrease after the intervention. Massage, an easy and low-cost method, is helpful for pain reduction in unconscious patients admitted to the intensive care units. Regarding the importance of pain control in patients admitted to the intensive care units and considering few studies in the field of complementary medicine and massage therapy on patients admitted to ICU, researchers interested in the field of complementary medicine are recommended to do studies with a larger sample size in different environments and research communities. Further studies are recommended to clarify the effect of massage therapy on other symptoms of unconscious patients admitted to the intensive care units, including agitation, delirium, and intensive care unit-acquired weakness.

\section{Data Availability}

The data used to support the findings of this study are available from the corresponding author upon request.

\section{Conflicts of Interest}

The authors declare that they have no conflicts of interest.

\section{Acknowledgments}

We would thank all patients and nursing staff of the intensive care units of Shahid Bahonar Hospital for their cooperation. The approved research project code was 96000333.

\section{References}

[1] L. D. Urden, K. M. Stacy, and M. E. Lough, Critical Care Nursing, Mosby/Elsevier, Amsterdam, Netherlands, 2010.

[2] F. E. Büyükyilmaz and T. Aştı, "Postoperative pain characteristics in Turkish orthopedic patients," Pain Management Nursing, vol. 11, no. 2, pp. 76-84, 2010.

[3] M. Shahriari, A. Golshan, N. Alimohammadi, and S. Abbasi, "The effect of a pain management program on pain management in patients with decreased level of consciousness admitted in AL-ZAHRA hospital icus a clinical trial," $A n$ esthesiology and Pain, vol. 5, no. 1, pp. 36-45, 2014.

[4] C. Arbour, C. Gélinas, and C. Michaud, "Impact of the implementation of the critical-care pain observation tool (CPOT) on pain management and clinical outcomes in mechanically ventilated trauma intensive care unit patients: a pilot study," Journal of Trauma Nursing, vol. 18, no. 1, pp. 52-60, 2011.

[5] H. Wøien, A. Stubhaug, and I. T. Bjørk, "Analgesia and sedation of mechanically ventilated patients-a national survey of clinical practice," Acta Anaesthesiologica Scandinavica, vol. 56, no. 1, pp. 23-29, 2012.

[6] D. T. Li and K. Puntillo, "A pilot study on coexisting symptoms in intensive care patients," Applied Nursing Research, vol. 19, no. 4, pp. 216-219, 2006.

[7] Y. Çirak, G. Yelvar, A. Çirak, and B. Karadüz, "Pain assessment in the intubated and sedated intensive care patients," European Respiratory Journal, vol. 48, no. 60, 2016.

[8] K. A. Puntillo, A. Max, J.-F. Timsit et al., "Pain distress: the negative emotion associated with procedures in ICU patients," Intensive Care Medicine, vol. 44, no. 9, pp. 1493-1501, 2018.

[9] A. K. Langerud, T. Rustøen, C. Brunborg, U. Kongsgaard, and A. Stubhaug, "Prevalence, location, and characteristics of chronic pain in intensive care survivors," Pain Management Nursing, vol. 19, no. 4, pp. 366-376, 2018.

[10] H. Devine, T. Quasim, J. McPeake, M. Shaw, L. Mccallum, and P. Mactavish, "Chronic pain in intensive care unit survivors: incidence, characteristics and side-effects up to one-year postdischarge," Journal of Rehabilitation Medicine, vol. 18, no. 51, pp. 451-455, 2019.

[11] G. Mistraletti, M. Umbrello, V. Mariani et al., "Conscious sedation in critically ill patients is associated with stressors perception lower than assessed by caregivers," Minerva Anestesiologica, vol. 84, no. 10, pp. 1150-1159, 2018.

[12] J.-F. Payen and G. Chanques, "Pain assessment in the ICU can improve outcome," Clinical Pulmonary Medicine, vol. 19, no. 1, pp. 21-26, 2012.

[13] L. Rose, O. Smith, C. Gelinas et al., "Critical care nurses' pain assessment and management practices: a survey in Canada," American Journal of Critical Care, vol. 21, no. 4, pp. 251-259, 2012.

[14] H. C. Laycock and C. Bantel, "The value of pupillary dilation in pre-emptive analgesia: is there more to this than meets the eye?" Critical Care, vol. 17, no. 5, p. 178, 2013.

[15] G. Robleda, F. Roche-Campo, L. Membrilla-Martínez et al., "Evaluation of pain during mobilization and endotracheal aspiration in critical patients," Medicina Intensiva (English Edition), vol. 40, no. 2, pp. 96-104, 2016.

[16] J.-F. Payen, G. r. Chanques, J. Mantz et al., "Current practices in sedation and analgesia for mechanically ventilated critically ill patients-a prospective multicenter patient-based study," Anesthesiology, vol. 106, no. 4, pp. 687-695, 2007.

[17] P. L. Marino, Marino's the ICU Book, Lippincott Williams \& Wilkins, Philadelphia, PA, USA, 2013.

[18] T. Strøm, T. Martinussen, and P. Toft, "A protocol of no sedation for critically ill patients receiving mechanical ventilation: a randomised trial," The Lancet, vol. 375, no. 9713, p. $475,2010$.

[19] H. Azami, B. K. Paveh, M. Rezaei, and S. Samadzadeh, “The impacts of short-term foot massage on mean arterial pressure of neurosurgical patients hospitalized in intensive care units," Iranian Journal of Critical Care Nursing, vol. 8, no. 3, pp. 133-142, 2015.

[20] F. Yaghoubinia, A. Navidian, S. Sheikh, E. Safarzai, and S. M. N.-a-D. Tabatabaei, "Effect of music therapy and reflexology on pain in unconscious patients: a randomized clinical trial," International Journal of Medical Research \& Health Sciences, vol. 5, no. 9, pp. 288-295, 2016.

[21] C. Chanif, W. Petpichetchian, and W. Chongchareon, "Does foot massage relieve acute postoperative pain? A literature review," Nurse Media Journal of Nursing, vol. 3, no. 1, pp. 483-497, 2013. 
[22] V. Buttagat, W. Eungpinichpong, U. Chatchawan, and S. Kharmwan, "The immediate effects of traditional Thai massage on heart rate variability and stress-related parameters in patients with back pain associated with myofascial trigger points," Journal of Bodywork and Movement Therapies, vol. 15, no. 1, pp. 15-23, 2011.

[23] J. Vaillant, A. Rouland, P. Martigné et al., "Massage and mobilization of the feet and ankles in elderly adults: effect on clinical balance performance," Manual Therapy, vol. 14, no. 6, pp. 661-664, 2009.

[24] S. Babajani, H. Babatabar, A. Ebadi, H. Mahmoudi, and E. Nasiri, "The effect of foot reflexology massage on the level of pain during chest tube removal after open heart surgery," Journal of Critical Care Nursing, vol. 7, no. 1, pp. 15-22, 2014.

[25] H. Jamaati, A. Vahedian-Azimi, A. Ebadi et al., "Therapeutic effect of massage on the patients in intensive care unit," Archives of Critical Care Medicine, vol. 1, no. 1, 2015.

[26] L. A. Braun, C. Stanguts, L. Casanelia et al., "Massage therapy for cardiac surgery patients-a randomized trial," The Journal of Thoracic and Cardiovascular Surgery, vol. 144, no. 6, pp. 1453-1459, 2012.

[27] N. A. Al-Akour, M. Gharaibeh, and R. A. Al-Sallal, "Perception of Jordanian mothers to nursing support during their children hospitalisation," Journal of Clinical Nursing, vol. 22, no. 1-2, pp. 233-239, 2013.

[28] L. A. Ladak, S. S. Premji, M. M. Amanullah, A. Haque, K. Ajani, and F. J. Siddiqui, "Family-centered rounds in Pakistani pediatric intensive care settings: non-randomized pre- and post-study design," International Journal of Nursing Studies, vol. 50, no. 6, pp. 717-726, 2013.

[29] M. L. Mitchell and W. Chaboyer, "Family centred care-a way to connect patients, families and nurses in critical care: a qualitative study using telephone interviews," Intensive and Critical Care Nursing, vol. 26, no. 3, pp. 154-160, 2010.

[30] P. Black, J. R. P. Boore, and K. Parahoo, "The effect of nursefacilitated family participation in the psychological care of the critically ill patient," Journal of Advanced Nursing, vol. 67, no. 5, pp. 1091-1101, 2011.

[31] A. S. Al-Mutair, V. Plummer, A. O’Brien, and R. Clerehan, "Family needs and involvement in the intensive care unit: a literature review," Journal of Clinical Nursing, vol. 22, no. 1314, pp. 1805-1817, 2013.

[32] S. Kean and M. Mitchell, "How do intensive care nurses perceive families in intensive care? Insights from the United Kingdom and Australia," Journal of Clinical Nursing, vol. 23, no. 5-6, pp. 663-672, 2014.

[33] M. Mitchell, W. Chaboyer, E. Burmeister, and M. Foster, "Positive effects of a nursing intervention on family-centered care in adult critical care," American Journal of Critical Care, vol. 18, no. 6, pp. 543-552, 2009.

[34] A. Fakhr-Movahedi, M. Nobahar, and M. Bolhasani, "The effect of touch on the vital signs of agitated patients undergoing mechanical ventilation: an interventional study," The Journal of Urmia Nursing and Midwifery Faculty, vol. 12, no. 4, 2014.

[35] A. Akbar Keykha, A. Abbaszadeh, H. Enayati, F. Borhani, H. Rafiei, and B. M. K. Hoseini, "Applying the instruction of pain control and sedation of the patients hospitalized in intensive care unit," Iranian Journal of Critical Care Nursing, vol. 6, no. 4, pp. 249-258, 2013.

[36] A. Heidari, M. Dianati, and S. G. A. Mousavi, "Prevalence of delirium, its related factors and short-term outcomes in ICU wards of Kashan Shahid-Beheshti and Isfahan Kashani hospitals during 2012-2013," KAUMS Journal (FEYZ), vol. 18, no. 1, pp. 76-84, 2014.

[37] M. Rajabpour Nikfam, A. Ghanbari Khanghah, T. Khaleghdoost Mohammadi, E. Kazemnezhad Leili, and A. Ashraf, "Study of predictors of delirium incidence in hospitalized patients in intensive care units," Journal of Holistic Nursing and Midwifery, vol. 26, no. 3, pp. 25-35, 2016.

[38] H. Azami, B. Khaledi paveh, M. Rezaei, and S. Samadzadeh, "Short-term effect of foot massage on the values of arterial oxygen saturation in neurosurgical patients admitted to ICU," Journal of Paramedical Sciences \& Rehabilitation, vol. 4, no. 2, pp. 50-59, 2015.

[39] M. Adib-Hajbaghery, R. Rajabi-Beheshtabad, A. Abasi, and E. Azizi-Fini, "The effect of massage therapy by a nurse and the patient's companion on the anxiety of male patients hospitalized in CCU: a clinical trial," Iran Journal of Nursing, vol. 25, no. 78, pp. 72-83, 2012.

[40] H. Dehghani, H. Tavangar, and A. Ghandehari, "Validity and reliability of behavioral pain scale in patients with low level of consciousness due to head trauma hospitalized in intensive care unit," Archives of Trauma Research, vol. 3, no. 1, 2014.

[41] S. S. Najafi, F. Rast, M. Momennasab, M. Ghazinoor, F. Dehghanrad, and S. A. Mousavizadeh, "The effect of massage therapy by patients' companions on severity of pain in the patients undergoing post coronary artery bypass graft surgery: a single-blind randomized clinical trial," International Journal of Community Based Nursing and Midwifery, vol. 2, no. 2, pp. 128-35, 2014.

[42] S. M. Cutshall, L. J. Wentworth, D. Engen, T. M. Sundt, R. F. Kelly, and B. A. Bauer, "Effect of massage therapy on pain, anxiety, and tension in cardiac surgical patients: a pilot study," Complementary Therapies in Clinical Practice, vol. 16, no. 2, pp. 92-95, 2010.

[43] N. Imani, S. Shams, M. Radfar, H. Ghavami, and H. Khalkhali, "Effect of applying reflexology massage on nitroglycerin-induced migraine-type headache: a placebo-controlled clinical trial the," Journal of the Turkish Society of Algology, vol. 30, no. 3, pp. 116-122, 2018.

[44] R. Melzack and P. D. Wall, "Pain mechanisms: a new theory," Science, vol. 150, no. 3699, pp. 971-978, 1965.

[45] L. Lindgren, S. Rundgren, O. Winsö et al., "Physiological responses to touch massage in healthy volunteers," Autonomic Neuroscience, vol. 158, no. 1-2, pp. 105-110, 2010.

[46] B. A. Bauer, S. M. Cutshall, L. J. Wentworth et al., "Effect of massage therapy on pain, anxiety, and tension after cardiac surgery: a randomized study," Complementary Therapies in Clinical Practice, vol. 16, no. 2, pp. 70-75, 2010. 